\title{
A Study on English Translation Tactics of the Report on the Work of the Government 2021 from the Perspective of Eco-Translatology
}

\author{
Junfang Mu${ }^{1}$, Qingqing Zhang1, Guang Yang² \\ ${ }^{1}$ College of Foreign Languages, Hebei University, Baoding, China \\ ${ }^{2}$ The State Key Laboratory of Alternate Electrical Power System with Renewable Energy Sources, North China Electric Power \\ University, Baoding, China \\ Email: Junfangmu@163.com
}

How to cite this paper: Mu, J.F., Zhang, Q.Q. and Yang, G. (2021) A Study on English Translation Tactics of the Report on the Work of the Government 2021 from the Perspective of Eco-Translatology. Open Access Library Journal, 8: e7990.

https://doi.org/10.4236/oalib.1107990

Received: September 22, 2021

Accepted: October 17, 2021

Published: October 20, 2021

Copyright $\odot 2021$ by author(s) and Open Access Library Inc.

This work is licensed under the Creative Commons Attribution International License (CC BY 4.0).

http://creativecommons.org/licenses/by/4.0/

\begin{abstract}
The Report on the Work of the Government is one of the important channels to convey China's views and positions to the international community, and it is also an important window to shape China's good image in the international community. The Report on the Work of the Government 2021 is a good material to study international publicity translation in that it involves China's politics, economy, culture and ecology, which contains many specialized words with Chinese cultural characteristics. Therefore, based on the theory of Eco-Translatology, this paper compares the Chinese and English versions of the report and explores the translation tactics of outreach materials from three dimensions: language, culture and communication. Results show that the translation of some specific terms in the report follows the principle of "three-dimensional" transformation in Eco-Translatology. Its translation not only expresses the connotation of Chinese culture effectively, but also fully realizes the equivalence of communicative intention through appropriate expressions, and roughly achieves correspondence and balance in linguistic dimension, cultural dimension, and communicative dimension. This study can help translator better grasp the translation tactics of the Report on the Work of the Government from the perspective of Eco-Translatology, and also provide references for the better translation of political texts in the future.
\end{abstract}

\section{Subject Areas}

Linguistics

\section{Keywords}

Eco-Translatology, “Three-Dimensional” Transformation, Report on the 
Work of the Government 2021, International Publicity Translation

\section{Introduction}

In the last 100 years, China has significantly enhanced its international status in that it has undergone dramatic positive changes in the political, economic and cultural fields, while it also faces the urgent task to improve the adverse public opinion environment in the world. Therefore, China needs to pour attention into international publicity, and focus on improving the appeal of Chinese culture, the affinity of China's image and the guidance in the international community. Chairman $\mathrm{Xi}$ Jinping stresses that there was a need to enhance international publicity, to promote the international discourse right that matches our comprehensive international strength and international status, and to build a sound environment of public opinion for the reform, development and stability of China [1]. As a typical outreach material, the Report on the Work of the Government 2021 reviews the main work of the Chinese government, covering specific initiatives, achievements made for 2020 and main goals for 2021. It is one of the important windows for China to convey its political ideas in the world, and also provides a significant channel for the international community to track China's future development plans. The Report on the Work of the Government cuts across all sectors of China's politics, economy, culture and ecology, and contains quite a few words with Chinese cultural characteristics, especially those words related to ecological civilization and environmental protection. Therefore, starting from the Chinese and English versions of the Report on the Work of the Government 2021 published by Xinhua News Agency, this paper attempts to summarize the characteristics of words and phrases in the report, and dig out the translation strategy based on the principle of "three-dimensional" transformation in Eco-Translatology, so as to explore the translation strategies of foreign publicity texts, hoping to provide a reference for the translation of other similar foreign publicity materials.

The remainder of this paper is structured as follows. First, a brief introduction of the translation principle of "three-dimensional" transformation in Eco-Translatology is presented (Section 2). Section 3 describes linguistic features of the Report on the Work of the Government 2021. Section 4 analyzes the translation strategies of the Report on the Work of the Government 2021 from the perspective of "three-dimensional" transformation. Then, the paper concludes with the research findings, limitations and possible lines for future research (Section 5).

\section{The Translation Principle of "Three-Dimensional" Transformation in Eco-Translatology}

Eco-Translatology, proposed in the early 21st century, is a new translation research paradigm from the ecological perspective with the main goal of revealing 
and illustrating translational ecology and translation theory [2]. Eco-Translatology is based on the isomorphism of translational ecology and natural ecology with ecological rationality. It employs ecological terms and conceptual words to create ecological discourses [3]. The translation methods of Eco-Translatology embody in three-dimensional transformation, that is, the adaptive selection transformation in language form, cultural connotation and communicative intention [4]. Linguistic dimension, cultural dimension and communicative dimension do not exist in isolation but permeate and interweave with each other, leading translators to make adjustments in the translation process. Among them, the linguistic dimension gives priority to the formal equivalence and language expression; cultural dimension highlights the transmission of cultural connotation; communicative dimension stresses the communicative function and expressive effect of the translation. Specifically, the translation method is summarized as the "threedimensional" transformation of linguistic dimension, cultural dimension and communicative dimension, which is taken into account from the following four aspects. First, from the practical point of view, language, culture and communication have always been the key points valued by translators. Translators often make adaptive selection according to the differences in language, culture and communication by means of domestication or foreignization. Second, from the theoretical point of view, the translation methods of culturology and linguistics are based on the methodical study of translation. Third, from the logical point of view, translation is the transformation of languages, while language is the carrier of culture, and culture is the accumulation of communication, so language, culture and communication are logically closely related. Fourth, from the perspective of maintaining "text ecology", translators can make use of "selective adaptation" and "adaptive selection" to keep the balance between different languages in linguistic ecology, cultural ecology and communicative ecology [5]. "Selective adaptation" and "adaptive selection" refer to the translator's choice of words in the translation process based on the relationship between the source language and the target language, so as to keep the balance in the translation process [6]. Translation is the transformation between different languages and the exchange of different cultures. Translators need to make multi-dimensional adaptive selections and transformation between the source language and the target language on the basis of adapting to the ecological translation environment [7]. Eco-Translatology attaches great importance to the living situation of translators and the development of their translation ability [8]. Therefore, successful translation requires translators to be familiar with different cultures, grasp the cultural connotations, and make "selective adaptation" and "adaptive selection" under different cultural backgrounds, to attain the faithfulness, smoothness and beauty of translation in Chinese cultural vocabulary.

\section{Linguistic Features of the Report on the Work of the Government 2021}

The Report on the Work of the Government 2021 mainly reviews the achieve- 
ments of the government in 2020, summarizes the main experiences gained in last year's work, and further points out the existing problems. It proposes the work arrangements for 2021 and develops the overall vision for the next five years. The language of the report is concise, precise and focused with selective words. The style of writing is simple and plain with simple sentences mostly employed, among which many sentences without subjects reflect certain objectivity. As an official document issued by the state, its terminology employs a large number of political terms with Chinese characteristics, such as “六稳”, “六保”, and “放管服”. In sum, the report is characterized by the content of government policy with strong directional measures, full of standardized words, quotations and classics with specific Chinese characteristics. The English version requires translators to accurately grasp the profound meaning of the source text, and to carefully select appropriate expressions that are easy for readers to comprehend under different cultural backgrounds, thus reflecting the strategy of China's external publicity and the level of humanistic construction.

\section{An Analysis of Translation Strategies of the Report on the Work of the Government 2021 from the Perspective of "Three-Dimensional" Transformation}

\subsection{Linguistic Dimension}

Chinese is parataxis with many short sentences while English is hypotaxis with a great deal of long sentences. Wang $\mathrm{Li}$, a famous linguist in China, illustrates that western languages are governed by law, while Chinese are governed by man in terms of sentence structure [9]. Because Chinese is ruled by man, the semantic meanings of discourses are directly expressed by various short sentences without conjunctions. Because English is the language ruled by law, so long as there are no errors in the sentence structure, a long sentence may contain many potential meanings. For this reason, the Chinese version of the Report on the Work of the Government 2021 often involves many short, concise, and precise sentences, while the corresponding English version often employs a great deal of complicated and long sentences. For example:

(1) Source Text (ST): 广大人民群众勤劳付出、共克时艰, 诠释了百折不挠 的民族精神。

Target Text (TT): Our people worked hard and fought adversity in close solidarity and with the unyielding spirit of the Chinese nation.

In example (1), Chinese phrases such as “勤劳付出” are endowed with loose sentence structures. The English version employs typical long sentences, which consists of 19 words without any punctuation marks in the middle. In this way, the meaning of those Chinese phrases is transformed into a whole sentence by means of different grammatical structures.

Secondly, Chinese version employs short sentences or parallel predicates with conjunctions. Therefore, we need to figure out the real meaning of the report based on context and culture. English, as a hypotaxis language, has obvious 
morphological marks to connect various components in the sentence, whose structure is compact and distinct. Therefore, taken context into consideration, the corresponding English version often adopts subordinate structures to underline the key points. For example:

(2) ST: 交出一份人民满意、世界瞩目、可以载入史册的答卷。

TT: Our achievements, which have won the approval of our people and global recognition, will be remembered in history.

In example (2), the structure of source language is relatively loose with parallel phrases employed. When translated into English, the subordinate structure is guided by "Which-" phrases, making the hierarchy clearer. Although the whole sentence looks more complicated on the surface, it is presented in a more logical and structured way with close connection.

In addition, the translator should strive to keep the balance of word meaning and sentence meaning between the source language and the target language, so as to achieve the ecological balance of language. English and Chinese belong to two different language systems, which are quite different in pronunciation, intonation, and grammar. Therefore, the translator needs to dig out the semantic connotation and realize the dynamic equivalence between the source language and the target language in terms of meaning and expression as much as possible. For example:

(3) ST: 污染防治力度加大, 资源能源利用效率显著提升, 生态环境明显改 善。

TT: Pollution prevention and control efforts were intensified, resources and energy were used more efficiently, and there was a notable improvement in the environment.

In example (3), three short sentences in Chinese version keep formal correspondence through three short sentences in English. The source language and the target language achieve semantic and structural equivalence, especially in the translation of words. The noun components in the first two short sentences are connected by the conjunction "and", so the translation achieves the coordination in vocabulary, syntax, and even style between different languages, thus attaining the transformation of linguistic dimension.

\subsection{Cultural Dimension}

The adaptive selection based on cultural dimension intends to illustrate the concrete connotation of different culture. Generally speaking, because of differences in culture, translators should pay attention to the cultural adaptation in the process of translation in order to alleviate and reduce the misunderstanding caused by cultural differences. Before translation, translators must read through relevant materials extensively, master the similarities and differences in cultures, and strive to create the translations that conform to the cultural habits of both sides. There are many specific words with Chinese characteristics and allusions and proverbs with rich cultural connotations. Accordingly, translators need to 
trace back to the source, accurately grasp the cultural differences, find out the cultural connotations in proverbs and allusions, and select appropriate words to convey the message.

(4) ST: 坚决打好三大攻坚战…...

TT: We made decisive progress in the three critical battles against poverty, pollution and potential risk...

In example (4), the phrase “三大攻坚战” is the expression with Chinese cultural connotation. In the report, the phrase “三大攻坚战” is translated as “three critical battles against poverty, pollution and potential risk". The translator uses English prepositional phrases to supplement the meaning of "poverty alleviation, pollution prevention and potential risk" in the English version, which more clearly introduces the culture, thus convenient for foreign readers to understand.

（5） ST: ……通过易地扶贫搬迁摆脱了 “一方水土难养一方人” 的困境。

TT: ...were relocated from inhospitable areas.

In example (5), the common saying “一方水土养一方人” means that a specific environment brings up a number of talents. This saying comes from Scattering Fire (《播火记》) written by Liang Bin. The report adds the adjective word “难” based on this saying and the source text turns out to be the sentence “一方 水土难养一方人”. After fully comprehending the meaning of this saying, the translator accurately delivers the connotation of the word “难” in the source text, and finally accurately deliver the connotation through the concise English expression "inhospitable areas", thus realizing the transformation in terms of cultural dimension.

\subsection{Communicative Dimension}

Translation is a cross-language communicative activity. Peter Newmark, a famous translator, once suggested that the effect of the translation on the readers of target language should be as equal to the readers of source language as much as possible, so as to realize the communicative equivalence between two countries with different languages [10]. Communicative dimension emphasizes the communicative function of translation, and requires translators not only to highlight the expressive focus of the source text, but also to switch flexibly from the role of translator, reader and even author. The effect of the translation on the readers of target language should be the same as that on the readers of source language. The fact that whether the author's communicative intention in the source language is reflected in the target language is a focus in communicative dimension. It also pays attention to whether the communicative intention of cultural form and cultural connotation in the source language has been conveyed to target language readers, and focuses on the smooth communication of cultural connotation under different cultural backgrounds. For example:

(6) ST: ……坚持不搞 “大水漫灌” …...

TT: ...we refrained from adopting a deluge of strong stimulus policies...

In example (6), the Chinese expression “大水漫灌” is the method of irrigation 
in agricultural production, which not only wastes water, but also frequently causes secondary salinization of soil under drought conditions. It is used in the report to describe those strong stimulus policies of quantitative easing. This metaphorical or figurative expression in official documents, if translated into English literally, will eventually point at another thing that does not match the original meaning in Chinese version, thus failing to realize the communicative intention of the source language and the target language. Therefore, the translator needs to take the denotative meaning of the noun in the actual context into consideration. If the literal meaning of the source language text is mechanically copied and translated into "Irrigation by flooding", the readers of target language will have deviations in understanding and the translation results will go against the transmission of the true communicative intention of the source language text. Therefore, the translator uses the metaphorical expression of "deluge" referring to “大水漫灌” in Chinese, and employs the phrase “a deluge of strong stimulus policies" to accurately convey the denotation that a large number of strong stimulus policies come from all over the place.

(7) ST: ……贫困村挂牌督战…..

TT: ...villages in poverty were placed under special supervision...

In the source text, the expression “挂牌督战” refers to a general who is personally on the front line to supervise the battle. By carefully analyzing the context, the translator digs out that in the report, the expression “挂牌督战” is intended to describe the task under the special supervision of higher authorities. Therefore, in order to highlight this communicative intention, the translator transforms it into the expression "were placed under special supervision". This communicative translation does not stick to the lexical-syntactic structure of the source text, but focuses more on the effect of the translation on the readers of target language. The translator emphasizes the author's communicative intention by delivering the connotative meaning of the expression, and eliminating reading misunderstanding or communicative barriers for the readers as much as possible. In sum, translators should take into account the communicative intention that the author aimed to achieve in the source text, and avoid over-explanation or inadequate expression in the translation, so that the translation can fully and accurately convey the communicative intention of the source text.

\section{Conclusion}

The Report on the Work of the Government, as the official publicity material for the world to learn about China, is one of the important windows to convey China's political views to the international community. The Report on the Work of the Government 2021 manifests unique linguistic features in the content and represents the authority and authenticity in its political status. As an outreach material of great significance, its English version provides an important channel for the world to understand China's future development plan. Therefore, based on the Report on the Work of the Government 2021, this paper attempts to 
summarize the characteristics of specific words and phrases in the text and explores the translation strategies of external publicity texts from three dimensions: linguistic dimension, cultural dimension and communicative dimension. The result shows that, in the English version, the translation of some cultural words follows the principle of "three-dimensional" transformation. The translation of the report can not only fully realize the equivalence of communicative intention, but also publicize Chinese culture well in that it achieves the balance from the perspectives of linguistic dimension, cultural dimension and communicative dimension. Therefore, based on the principle of "three-dimensional" transformation in Eco-Translatology, this study figures out the translation strategies of the Report on the Work of the Government. We believe that the results of our study can provide a reference for translators to improve the translation of publicity materials, better introducing China's development plan by achieving the balance in translation from the perspectives of linguistic dimension, cultural dimension and communicative dimension. This study is not, however, without limitations. The main limitation is that the research selects only specific words with Chinese characteristics as a research subject and picks out some typical examples in the Report on the Work of the Government 2021 to analyze, yet the number of examples used in the paper is still not enough to reach a much more convincing conclusion. Therefore, it would be desirable to expand the study with a larger selection of cultural words with Chinese characteristics which belong to different political documents, to see if the translation strategies that we have identified correspond to the general situation of various publicity materials.

\section{Acknowledgements}

This research was supported by Social Science Fund of Hebei Province (HB18YY005).

\section{Conflicts of Interest}

The authors declare no conflicts of interest.

\section{References}

[1] Xinhua News Agency (2021) In the 30th session of the Political Bureau of the CPC Central Committee, Xi Jinping emphasizes to Strengthen and Improve the International Communication to Show a True, Three-Dimensional and Comprehensive China. People's Daily, 2 June. (In Chinese) http://www.renminrb.com/renminribao/157840602.html

[2] Luo, D.J. (2021) The Interpretation of the Complexity of Eco-Translatology from the Perspective of Complex Adaptive System. Shandong Foreign Language Teaching, 3, 98-107.

[3] Huang, C.F. (2021) A Study on Constructive Postmodern Thoughts of Eco-Translatology. Foreign Language Research, 4, 45-50.

[4] Hu, G.S. (2008) On Translation Theory from Terms: An Overview of Translation Adaptation and Choice Theory. Shanghai Journal of Translators, 2, 1-5. 
[5] Hu, G.S. (2013) Eco-Translatology: Construction and Interpretation. The Commercial Press, Bejing.

[6] Hu, G.S. (2006) Illustrate the Translation Principles and Methods of "Adaptive Selection Theory”. Foreign Language Teaching and Research, 3, 49-52+65.

[7] Liu, F. (2021). A Study on the Translation of "Red Sorghum Family" from the Perspective of Three-Dimensional Transformation of Eco-Translatology. Open Journal of Social Sciences, 9, 25-31. https://doi.org/10.4236/jss.2021.96003

[8] Mu, J.F., Chen, Y.Y. and Yang, G. (2021) A Scientometric Analysis of Research Advances in China's Eco-Translatology Studies (2008-2021). Open Access Library Journal, 8, e7791. https://doi.org/10.4236/oalib.1107791

[9] Wang, L. (1984) Collected Works of Wang Li Vol. 1-Chinese Grammar Theory. Shandong Education Press, Shandong.

[10] Newmark, P. (2001) Approaches to Translation. Shanghai Foreign Language Education Press, Shanghai. 